\title{
Alfentanil infusion for sedation in infants and small children during cardiac catheterization
}

Paula Rautiainen MD

\begin{abstract}
We have analyzed several sedation techniques for paediatric cardiac catheterization which offer stable conditions for a few hours investigation, and maintain spontaneous breathing. In the present study, after premedication with oral flunitrazepam 0.1 $\mathrm{mg} \cdot \mathrm{kg}^{-1}, 14$ children aged $1-17$ mo were sedated with an individually titrated alfentanil infusion. Every patient was sedated to a level which produced no reaction to pain or any discomfort. The induction dose and the maintenance requirement of alfentanil were $24 \pm 8 \mu \mathrm{g} \cdot \mathrm{kg}^{-1}$ and $32 \pm 8$ $\mu \mathrm{g} \cdot \mathrm{kg}^{-1} \cdot \mathrm{hr}^{-1}$ (mean $\pm \mathrm{SD}$ ), respectively. These doses were less in cyanotic than in acyanotic patients: $21 \pm 6$ vs $28 \pm 8$ $\mu \mathrm{g} \cdot \mathrm{kg}^{-1}$ and $29 \pm 10 \mathrm{vs} 34 \pm 3 \mu \mathrm{g} \cdot \mathrm{kg}^{-1} \cdot \mathrm{hr}^{-1}$, respectively $(P<0.05)$. The mean plasma concentration of alfentanil during maintenance of sedation was $79 \pm 23 \mathrm{ng} \cdot \mathrm{ml}^{-1}$. Ventilation of two children was assisted for a short time after an incremental bolus of alfentanil. It is concluded that an alfentanil infusion technique with close monitoring of breathing is a practical sedation method for paediatric cardiac catheterization.
\end{abstract}

Nous avons évalué plusieurs techniques de sédation appropriées au cathétérisme cardiaque chez les enfants. La technique idéale doit produire une condition stable pendant quelques heures chez un enfant qui respire spontanément. Au cours de cette étude. après une prémédication au flunitrazépam oral à raison de 0,1 $m g \cdot \mathrm{kg}^{-1}$, on titrait de l'alfentanil par voie intraveineuse chez 14 enfants agés de 1 à 17 mois de telle sorte qu'ils ne réagissent ni d la douleur ni à l' inconfort. Les doses moyennes d' induction

\section{Key words}

ANAESTHESIA: paediatric;

ANAESTHETIC TECHNIQUES: intravenous;

ANAESTHETICS, INTRAVENOUS: alfentanil;

HEART: catheterization.

From the Department of Anaesthesia, Children's Hospital, University of Helsinki, SF-00290 Helsinki, Finland.

Address correspondence to: Dr. Paula Rautiainen,

Children's Hospital, SF-00290 Helsinki, Finland.

Accepted for publication 3rd June, 1991. et de maintien nécessaires furent respectivement de $24 \pm 8$ $\mu \mathrm{g} \cdot \mathrm{kg}^{-1}$ et de $32 \pm 8 \mu \mathrm{g} \cdot \mathrm{kg}^{-1} \cdot \mathrm{h}^{-1}$ (moy \pm écart-type). Toutefois, elles étaient moins grandes chez les enfants cyanotiques que chez les autres, soit: $21 \pm 6$ vs $28 \pm 8 \mu \mathrm{g} \cdot \mathrm{kg}^{-1}$ et 29 \pm 10 vs $34 \pm 3 \mu \mathrm{g} \cdot \mathrm{kg}^{-1} \cdot h^{-1}$, respectivement. La concentration plasmatique moyenne d'alfentanil pendant la phase de maintien était de $79 \pm 23 \mathrm{ng} \cdot \mathrm{ml}^{-1}$. Après un bolus supplémentaire d'alfentanil, on dut assister la ventilation de deux enfants pendant quelques instants. Donc, l'infusion d'alfentanil couplé $\grave{a}$ un monitorage serré de la respiration constitue une technique de sédation pratique pour le cathétérisme cardiaque chez les enfants.

Little has been documented of the different anaesthesia techniques for paediatric cardiac catheterization. ${ }^{~}$ General anaesthesia, a combination of meperidine, promethazine and chlorpromazine, ketamine, as well as opioids have been described but not universally accepted. ${ }^{2,3}$ In an earlier study, a bolus technique with alfentanil or fentanyl was used. However, several peaks and troughs were seen when alfentanil was administered in incremental doses. Also the need to repeat doses every six to nine minutes to maintain a steady level of sedation was considered unpractical. ${ }^{2}$ In the present study, an alfentanil infusion technique was evaluated for sedation in infants and small children undergoing cardiac catheterization. The doserequirement of alfentanil was titrated, and plasma concentrations during a stable level of sedation were measured.

\section{Methods}

Fourteen consecutive ASA physical status III patients of less than two years of age admitted for elective cardiac catheterization were studied. Institutional Ethics Committee approval and informed consent from parents were obtained for the study. Patients with chromosome or other multiple anomalies, or hepatic or renal dysfunction, were excluded.

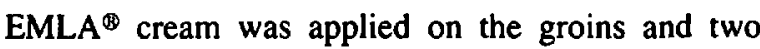
extremities two hours before the patient arrived at the 
cardiac laboratory. Half an hour after oral premedication (flunitrazepam solution $0.1 \mathrm{mg} \cdot \mathrm{kg}^{-1}$ ), a peripheral iv cannula was inserted and a 5\% dextrose infusion with 60 $\mathrm{mmol} \cdot \mathrm{L}^{-1}$ of $\mathrm{NaCl}$ was started at the rate of $4 \mathrm{ml}$. $\mathrm{kg}^{-1} \cdot \mathrm{hr}^{-1}$. Glycopyrrolate $5 \mu \mathrm{g} \cdot \mathrm{kg}^{-1}$ was given iv. Thereafter, the patients were given incremental doses of alfentanil $3-5 \mu \mathrm{g} \cdot \mathrm{kg}^{-1}$ every two to three minutes to induce a level of sedation that allowed preparation of the skin and positioning of the patient without reaction. The groins were infiltrated with one per cent lidocaine for femoral vascular access.

After induction, an infusion of alfentanil $30 \mu \mathrm{g}$. $\mathrm{kg}^{-1} \cdot \mathrm{hr}^{-1}$ was started to maintain a satisfactory level of sedation. This dose was chosen from the earlier report which used alfentanil increments in the same age group. ${ }^{2}$ The anaesthetist continuously evaluated patient's reactiveness and the level of sedation according to the scales in Table I. The level of sedation was considered satisfactory if both reactiveness and sedation scores were $\geq 4$. If the patient reacted to pain or discomfort, an additional increment of alfentanil 3-5 $\mu \mathrm{g} \cdot \mathrm{kg}^{-1}$ was given, and the infusion was increased by $3-5 \mu \mathrm{g} \cdot \mathrm{kg}^{-1} \cdot \mathrm{hr}^{-1}$. On the other hand, if the sum of two scores was ten for more than ten minutes, the alfentanil infusion was decreased by 3-5 $\mu \mathrm{g} \cdot \mathrm{kg}^{-1} \cdot \mathrm{hr}^{-1}$ to avoid unnecessarily deep level of sedation.

Patients breathed $30 \%$ oxygen in air spontaneously via a transparent face mask. If apnoea for more than $15 \mathrm{sec}$ was noticed, breathing was assisted manually with a Jackson-Rees T-piece system. Haemodynamic catheterization consisted of either arterial or venous cannulations, or both, as well as of shunt and pressure measurements, and at least two different angiograms. For four-chamber imaging, patients were positioned at a $30^{\circ}$ head-up position, because the $x$-ray tube directions could not be altered.

The ECG, heart rate, arterial oxygen saturation (Biox 3700, Ohmeda), end-tidal carbon dioxide (Normocap, Datex) and rectal temperature were monitored continuously. End-tidal carbon dioxide was sampled via an adaptor located $5 \mathrm{~mm}$ inside the nostril with a continuous flow of $200 \mathrm{ml} \cdot \mathrm{min}^{-1}$. Noninvasive arterial pressure (Dinamap, Criticon) was recorded every five minutes. Arterial blood gases were analyzed at least once during a steady level of sedation, and a simultaneous end-tidal carbon dioxide was documented. Before the angiograms, at a steady level of sedation, a venous blood sample was drawn to determine alfentanil plasma concentration. After hexane-ethanol extraction of the plasma samples, and dissolution into pentadecane, plasma concentrations were measured with a Hewlett-Packard 5730A gas chromatograph equipped with an HP $1874 \mathrm{~B}$ capillary column control unit and nitrogen sensitive detector at the column
TABLE I Scales used to evaluate patient's reactiveness and the level of sedation

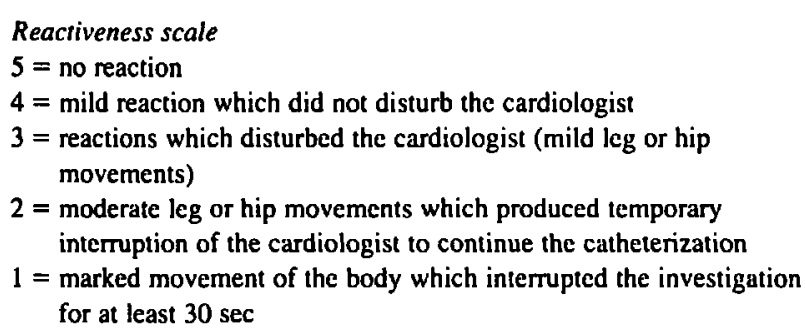

Sedation scale

$5=$ not rousable

4 = rousable if shaken vigoursly

$3=$ wakes up if shaken mildly or spoken to with loud voice

2 = opens eyes spontaneously or when asked

1 = awake but mildly sedated

temperature of $245^{\circ} \mathrm{C}{ }^{4}$ The limit of sensitivity was 1 $\mathrm{ng} \cdot \mathrm{ml}^{-1}$.

After catheterization, patients stayed in the recovery room until the pressure bandage was removed and the patient was awake. Thereafter, feeding was allowed without restriction. Difficulties with feeding or voiding were documented on the perioperative day.

The variations of individual arterial pressures and heart rates during sedation were evaluated for every patient by dividing the standard deviation (SD) of individual pressure and heart rate readings taken at five-minute intervals by their mean values. The individual induction and maintenance doses of alfentanil were calculated. The maintenance dose was the cumulative total alfentanil requirement after induction divided by the duration of sedation. Dose-effect curves were drawn by using a log-probit transformation. ${ }^{5}$ Plasma clearance of alfentanil was calculated as the maintenance dose divided by the plasma concentration taken during a stable level of sedation when at least 20 minutes had elapsed since an infusion rate adjustment. ${ }^{6}$ Dose-requirements, plasma concentrations at steady level of sedation, as well as calculated plasma clearances of alfentanil were compared between the cyanotic and acyanotic, as well as between the patients with or without digitalis or furosemide therapy, by using Student's t test with Bonferroni correction. Mean values $\pm \mathrm{SD}$ are shown. $P<0.05$ was considered to be statistically significant.

\section{Results}

The patient data are shown in Table II: seven patients were cyanotic, ten were digitalized and six received furosemide. Mean duration of catheterization was $2.4 \pm 0.6 \mathrm{hr}$. A satisfactory level of sedation was maintained with alfentanil in every patient. After induction, the scores of 
TABLE II Patient characteristics

\begin{tabular}{rlllll}
\hline & $\begin{array}{l}\text { Age } \\
\text { \# }\end{array}$ & $\begin{array}{l}\text { Weight } \\
\mathrm{kg}\end{array}$ & Diagnosis & Cyanosis & Medication \\
\hline 1 & 0.08 & 2.85 & TGA+DORV & yes & DF \\
2 & 0.12 & 3.60 & VSD+ASD & no & DF \\
3 & 0.17 & 4.93 & TGA+DORV & yes & DF \\
4 & 0.21 & 5.02 & TGA+PDA & yes & D \\
5 & 0.25 & 5.27 & TGA+TI & yes & \\
6 & 0.29 & 5.60 & TOF & yes & P \\
7 & 0.42 & 5.07 & VSD+DORV & no & DF \\
8 & 0.46 & 7.08 & TOF & yes & P \\
9 & 0.58 & 6.04 & VSD & no & D \\
10 & 0.67 & 5.63 & TGA+VSD+PS & yes & DF \\
11 & 0.75 & 5.85 & VSD+PH & no & DF \\
12 & 0.83 & 6.65 & VSD+PH & no & \\
13 & 1.17 & 6.12 & VSD+PH & no & D \\
14 & 1.42 & 12.10 & VSD & no & D \\
\hline
\end{tabular}

Abbreviations: $\mathrm{ASD}=$ atrial septal defect, $\mathrm{DORV}=$ double outlet right ventricle, $\mathrm{PDA}=$ patent ductus arteriosus, $\mathrm{PH}=$ pulmonary hypertony, $\mathrm{PS}=$ pulmonary stenosis, TGA = transposition of great arteries, $\mathrm{Tl}=$ tricuspid insufficiency, $\mathrm{TOF}=$ tetralogy of Fallot, VSD $=$ ventricular septal defect. Medication: $\mathrm{D}=$ digitalis,

$F=$ furosemide, $P=$ propranolol

patients' reactiveness and sedation throughout the catheterization were $\geq 4$. Mean systolic and diastolic arterial pressures were 81 and $44 \mathrm{mmHg}(10.8$ and $5.9 \mathrm{kPa}$ ), respectively, and mean heart rate 126 beats $\cdot \mathrm{min}^{-1}$. Mean variations of individual pressures and heart rate were $7 \%$, $13 \%$, and $7 \%$, respectively.

Mean arterial pH was $7.34 \pm 0.02$ and was not effected by cyanosis, digitalis or furosemide therapy. Mean arterial carbon dioxide tension was $45 \pm 4 \mathrm{mmHg}$ $(6.0 \pm 0.5 \mathrm{kPa})$. There was no difference between cyanotic and acyanotic patients. However, patients receiving digitalis or furosemide had greater arterial carbon dioxide tension, $46 \pm 4 \mathrm{mmHg}(6.1 \pm 0.5 \mathrm{kPa})$, than other patients, $43 \pm 2 \mathrm{mmHg}(5.7 \pm 0.3 \mathrm{kPa})(P<0.05)$.

Ventilation was assisted on two occasions due to apnoea. In one patient ventilation was assisted for less than one minute during induction, and in the other for three minutes during positioning to four-chamber imaging after an incremental alfentanil dose. Arterial oxygen saturation decreased by $15 \%$ and $20 \%$, respectively, and was rapidly corrected during the assisted ventilation.

The mean induction dose of alfentanil was $24 \pm 8$ $\mu \mathrm{g} \cdot \mathrm{kg}^{-1}$. The induction dose in acyanotic was greater than in cyanotic patients, $28 \pm 8 \mathrm{vs} 21 \pm 6 \mu \mathrm{g} \cdot \mathrm{kg}^{-1}(P<$ $0.05)$. Patients having digitalis or furosemide therapy had greater induction doses than the others, $26 \pm 7$ vs $18 \pm 6$ $\mu \mathrm{g} \cdot \mathrm{kg}^{-1}(P<0.001)$. The mean maintenance requirement of alfentanil was $32 \pm 8 \mu \mathrm{g} \cdot \mathrm{kg}^{-1} \cdot \mathrm{hr}^{-1}$. The maintenance dose was greater in acyanotic than in cyanotic patients, $34 \pm 3 \mathrm{vs} 29 \pm 10 \mu \mathrm{g} \cdot \mathrm{kg}^{-1} \cdot \mathrm{hr}^{-1}(P<$
TABLE III The plasma concentrations during stable sedation and calculated plasma clearances of alfentanil of the patients

\begin{tabular}{rll}
\hline$\#$ & $\begin{array}{l}\text { Concentration } \\
n g \cdot m l^{-1}\end{array}$ & $\begin{array}{l}\text { Clearance } \\
\mathrm{ml} \cdot \mathrm{kg}^{-1} \cdot \mathrm{min}^{-1}\end{array}$ \\
\hline 1 & 130.7 & 4.6 \\
2 & 100.1 & 5.2 \\
3 & 68.5 & 8.2 \\
4 & 49.5 & 3.1 \\
5 & 62.9 & 6.6 \\
6 & 223.4 & not calculated \\
7 & 73.8 & 8.2 \\
8 & 95.3 & 5.8 \\
9 & 64.3 & 8.0 \\
10 & 90.8 & 4.9 \\
11 & 55.3 & 11.0 \\
12 & 65.2 & 9.3 \\
13 & 70.4 & 7.9 \\
14 & 101.7 & 5.7 \\
\hline
\end{tabular}

0.05). Digitalis or furosemide therapy had no influence on the maintenance requirement of alfentanil. Dose-effect curves of the induction dose and maintenance requirement are presented in the Figure. During catheterization, the median number of individual infusion dose changes was one (range $0-4$ ), and of incremental boluses two (range $0-4)$.

The mean time from induction to the measurement of plasma concentration was $57 \pm 21$ min. Plasma concentrations during stable sedation and calculated clearances are shown in Table III. The value of patient \#6 was excluded from the results, because the concentration was more than six standard deviations from the mean. The mean alfentanil plasma concentration was $79 \pm 23$ $\mathrm{ng} \cdot \mathrm{ml}^{-1}$. Cyanosis or digitalis or furosemide therapy did not effect plasma concentration of alfentanil. Mean plasma clearance of alfentanil was $6.8 \pm 2.2 \mathrm{ml}$. $\mathrm{kg}^{-1} \cdot \mathrm{min}^{-1}$. Acyanotic patients had greater mean plasma clearance than cyanotic patients, $7.9 \pm 2.0$ vs $5.5 \pm 1.8$ $\mathrm{ml} \cdot \mathrm{kg}^{-1} \cdot \mathrm{min}^{-1}(P<0.001)$. The plasma clearance of patients receiving digitalis or furosemide therapy did not differ from the clearance of other patients. No correlation between the individual maintenance requirement and the steady sedation plasma concentration was found.

After catheterization, patients stayed in the recovery room for an average of 1.7 (range 1.0-2.3) hr. Every patient could be fed orally within the first few hours of return to their ward. Neither nausea or vomiting nor difficulties with voiding were reported.

\section{Discussion}

The goals of this study to evaluate an alfentanil infusion technique to produce sedation for small paediatric cardiac patients, to formulate guidelines for drug dosing, and to 


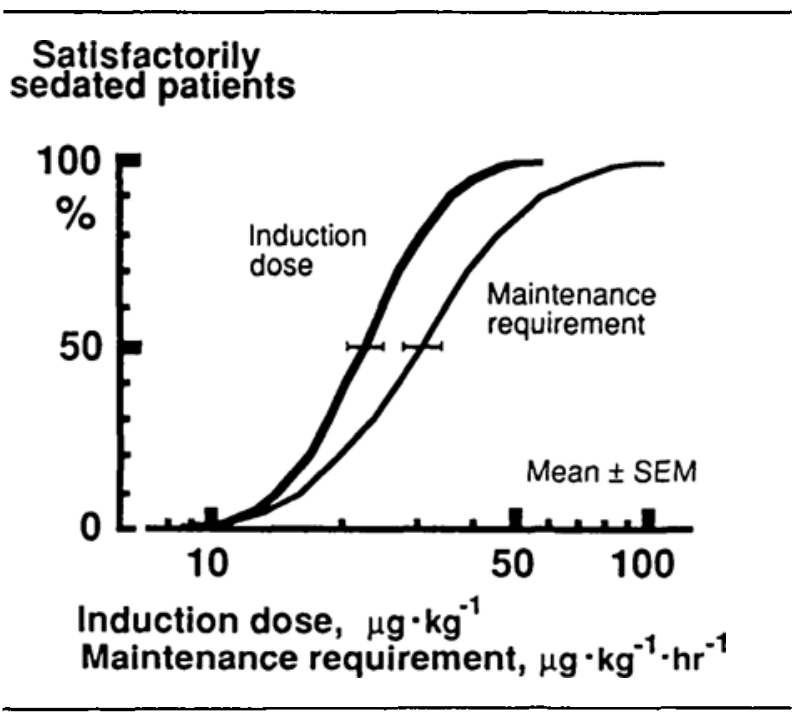

FIGURE Dose-effect curves of alfentanil to induce and maintain iv sedation for cardiac catheterization following flunitrazepam premedication.

measure the plasma concentrations of alfentanil during stable sedation were achieved. In every patient, an adequate level of sedation, which abolished reactions to noxious stimuli and maintained haemodynamic stability and normal blood gases, was titrated individually.

After flunitrazepam premedication, the mean induction dose of alfentanil was $24 \mu \mathrm{g} \cdot \mathrm{kg}^{-1}$. This was comparable to that reported earlier during cardiac catheterization ${ }^{2}$ but much lower than the induction dose for general anaesthesia. ${ }^{7,8}$ A new finding of smaller induction doses in cyanotic than in acyanotic patients can be explained by the rapid increase of brain concentration of alfentanil due to right to left shunting. ${ }^{9}$ The reason for a greater need of the drug by patients receiving digitalis or furosemide therapy may be an increased distribution volume or a decreased speed of circulation due to worse cardiac function in these patients. ${ }^{10}$

The mean requirement of alfentanil to maintain stable sedation, $32 \mu \mathrm{g} \cdot \mathrm{kg}^{-1} \cdot \mathrm{hr}^{-1}$, was similar to that in an earlier report when patients were titrated with repeated incremental doses. ${ }^{2}$ Mean plasma concentration during stable sedation in the present study, $80 \mathrm{ng} \cdot \mathrm{ml}^{-1}$, was less than reported during general anaesthesia, 200-500 $\mathrm{ng} \cdot \mathrm{ml}^{-1.7 .11}$ There is no need for profound anaesthesia during cardiac catheterization.

During stable sedation, the administered alfentanil replaces the amount eliminated from body which is equal to the plasma concentration multiplied by clearance. ${ }^{6}$ The mean plasma clearance of alfentanil in the present study was $6.8 \mathrm{ml} \cdot \mathrm{kg}^{-1} \cdot \mathrm{min}^{-1}$. This is in the same range $\left(4.7-11.1 \mathrm{ml} \cdot \mathrm{kg}^{-1} \cdot \mathrm{min}^{-1}\right)$ as reported earlier. ${ }^{12-16}$ However, this clearance value may overestimate the true metabolic clearance, since the formula used is correct only under steady-state conditions. In the present study, pharmacokinetic steady-state was never reached, but the clearance values in cyanotic and acyanotic children appear to be comparable because the same methodology was used for all patients. The estimation of the clearance was also hampered because the values were based on alfentanil concentrations measured in a single sample. Therefore, the present clearance values are only suggestive and cannot be compared reliably with previous studies. The finding of smaller plasma clearance of alfentanil in cyanotic infants and small children compared with their acyanotic counterparts has not been reported before. The pharmacokinetic behaviour of alfentanil has been analyzed only once in children with congenital heart disease. In that study, cyanotic and acyanotic patients constituted a single group. ${ }^{15}$ Decreased plasma clearance in cyanotic children is the probable reason for the smaller requirement of alfentanil to maintain steady sedation in these patients. More studies are required to investigate the pharmacokinetics of alfentanil in infants with congenital cyanotic and acyanotic heart malformations.

In one patient (Table III, patient \#6), an unexpectedly high plasma concentration was found and this patient was excluded from the plasma concentration and clearance results. There are two possible explanations: either the blood at the sampling site was mixed with direct venous flow from the alfentanil infusion, or the continuous esmolol infusion to control right ventricle infundibulum stenosis administered only for this patient might have had an effect on the measured concentration although there are no reports of interactions between esmolol and alfentanil.

Respiratory depression is a common, dose-related side-effect of opioids. ${ }^{17}$ Even a small $5 \mu \mathrm{g} \cdot \mathrm{kg}^{-1}$ dose of alfentanil may cause a rapid effect on respiration indicating the need for close monitoring of ventilation. Despite that, short periods of breath-holding related to incremental alfentanil doses may occur. ${ }^{2}$ In the present study, two brief periods of apnoea related to drug boluses were documented. During steady infusion of alfentanil, no apnoea was seen, and the average arterial carbon dioxide tension was normal. Mild hypoventilation was found in patients with furosemide or digitalis therapy, as documented earlier. ${ }^{2}$ This might be a compensation for furosemide-induced metabolic alkalosis or the result of chronic hypoventilation in these patients who have compromised cardiorespiratory function.

When administered by infusion, the alfentanil dose required to maintain satisfactory sedation needed to be changed only once or twice during catheterization. Thus, administration of the drug is easier than by incremental bolus doses which are required every six to nine minutes. ${ }^{2}$ The present results suggest that alfentanil infusion is a 
practical method to sedate spontaneously breathing infants and small children in a cardiac laboratory. However, close monitoring of ventilation and an understanding of the physiological differences between cyanotic and acyanotic patients are necessary.

\section{Acknowledgement}

Alfentanil concentrations were kindly measured by Orion Pharmaceutica, Espoo, Finland.

\section{References}

1 Freed MD. Cardiac catheterization. In: Adams FH, Emmanouilides GC, Riemenschneider TA (Eds.). Moss' Heart Disease in Infants, Children, and Adolescents, 4th ed., Baltimore: Williams \& Wilkins, 1989: 130-47.

2 Meretoja $O A$, Rautiainen $P$. Alfentanil and fentanyl sedation in infants and small children during cardiac catheterization. Can J Anaesth 1990; 37: 624-8.

3 Rheuban KS, Carpanter MA. Diagnostic cardiac cathetcrization, angioplasty, and interventional catheterization. In: Lake C (Ed.). Pediatric Cardiac Anesthesia. Norwalk: Appleton \& Lange, 1988: 55.

4 Hynynen M. Takkunen O, Salmenperä M, Haataja $H$, Heinonen $J$. Continuous infusion of fentanyl or alfentanil for coronary artery surgery. Br J Anaesth 1986; 58: 1252-9.

5 Litchfield JT, Wilcoxon F. A simplified method of evaluating dose-effect experiments. J Pharmacol Exp Ther 1949; 53: 99-113.

6 Gibaldi M, Perrier D. Pharmacokinetics. 2nd ed., New York: Marcel Dekker, 1982: 321.

7 Ausems ME, Hug CC Jr, Stanski DR, Burm AGL. Plasma concentrations of alfentanil required to supplement nitrous oxide anesthesia for general surgery. Anesthesiology 1986; 65: 362-73.

8 Bailey PL, Stanski TH. Pharmacology of intravenous narcotic anesthetics. In: Miller RD (Ed.). Ancsthesia, 2nd ed., New York: Churchill Livingstone, 1986; 1: 757.

9 Hickey $P R$, Wessel $D L$. Anesthesia for treatment of congenital heart disease: choice of anesthetic agents in congenital heart disease. In: Kaplan JA (Ed.). Cardiac Anesthesia. 2nd ed., Orlando: Grune \& Stratton, Inc., 1987: 2; 671-5.

10 Talner NS. Heart failure. In: Adams FH, Emmanouilides GC, Riemenschneider TA (Eds.). Moss' Heart Disease in Infants, Children and Adolescents.4th ed., Baltimore: Williams \& Wilkins, 1989: 890-911.

11 Stanski $D R, H u g C C J r$. Alfentanil - a kinetically predictable narcotic analgesic. Anesthesiology 1982; 57: 435-8

12 Meistelman C, Saint-Maurice C, Lepaul M, Levron J-C, Loose J-P, MacGee $K$. A comparison of alfentanil pharmacokinetics in children and adults. Anesthesiology 1987; 66: 13-6.
13 Goresky GV, Koren G, Sabourin MA, Sale JP, Strunin $L$. The pharmacokinetics of alfentanil in children. Anesthesiology 1987; 67: 654-9.

14 Roure P, Jean N, Leclerc A-C, Cabanel N, Levron J-C, Duvaldestin $P$. Pharmacokinetics of alfentanil in children undergoing surgery. Br J Anaesth 1987; 59: 1437-40.

15 den Hollander JM, Hennis PJ, Burm AGL, Bovill JG. Alfentanil in infants and children with congenital heart defects. Journal of Cardiothoracic Anesthesia 1988; 2: 12-7.

16 Davis PJ, Killian A, Stiller RL, Cook DR, Guthrie RD, Scierka $A M$. Pharmacokinetics of alfentanil in newborn premature infants and older children. Dev Pharmacol Ther 1989; $13: 21-7$.

17 Jaffe JH, Martin WR. Opioid analgesics and antagonists. In: Goodman Gilman A, Rall TW, Nies AS, Taylor P (Eds.). Goodman and Gilman's The Pharmacological Basis of Therapeutics. 8th ed., New York: Pergamon Press, 1990: 485-521. 